\title{
EFEKTIVITAS PEMBERIAN CITRUS BAKING SODATERHADAP PENGHILANGAN STAIN PADA PRIA PEROKOK USIA 20-55 TAHUN DI KELURAHAN TANJUNGBALAI KOTA II, Lk. III KECAMATAN TANJUNGBALAI SELATAN
}

\author{
Intan Aritonang, Devi Ray Syahfitri Sinulingga \\ Jurusan KeperawatanGigi Poltekkes Kemenkes Medan
}

\begin{abstract}
Citrus and baking soda are kitchen ingredients that are often found in everyday life, have ingredients that can blot stains on teeth, especially stains of cigarettes or stains that can affect the color of teeth. This type of research is analytic research with a quasi experiment method which aims to determine the effectiveness of giving citrus with baking soda to stain removal in smokers aged 20-55 years Tanjungbalai Kota II Village, Lk. III, South Tanjungbalai District with a sample of 30 people. The results showed that the average stain state before being given was given citrus gel with baking soda to smokers aged 20-55 years in Lk. III Kelurahan Tanjungbalai Kota II, Kecamatan Tanjungbalai Selatan, lobene intensity of 0.879, with lobene area of 1.084, and combined lobene of 0.081. Meanwhile for stain conditions after being given citrus gel with baking soda for smokers aged 20-55 years at Lk. III Kelurahan Tanjungbalai, Kecamatan Tanjungbalai Selatan, lobene intensity of 0.408, lobene area of 0.493, combined lobene of 0.037. That it is effective to give citrus baking soda gel to stain removal using the dependent $t$-test with a value of $p(0,000)<\alpha(0.05)$. This study concluded that the effectiveness of giving citrus with baking soda to stain removal. It is hoped that the community will use the gel as recommended.
\end{abstract}

Keywords : Citrus, Baking Soda, Stain Removal

\section{LATAR BELAKANG}

Kesehatan merupakan bagian terpenting dalam kehidupan manusia, sehat secara jasmani dan rohani.Kesehatan yang perlu diperhatikan selain kesehatan tubuh secara umum, juga kesehatan gigi dan mulut, karena kesehatan gigi dan mulut dapat mempengaruhi kesehatan tubuh secara menyeluruh. Dengan kata lain bahwa kesehatan gigi dan mulut merupakan bagian integral dari kesehatan tubuh secara keseluruhan yang tidak dapat dipisahkan dari kesehatan tubuh secara umum.

Untuk mencapai kesehatan gigi dan mulut yang optimal, maka harus dilakukan perawatan secara berkala, perawatan dapat dimulai dari memperthatikan diet makanan, jangan terlalu banyak makanan yang mengandung gula dan makanan yang lengket.Juga jaga kesehatan seperti mengurangi merokok atau tidak merokok untuk menjaga kesehatan tubuh serta kesehatan gigi dan mulut yang optimal.Pembersihan plak dan sisa makanan yang tersisa dilakukan dengan menyikat gigi, teknik dan caranya jangan sampai merusak struktur gigi dan gusi. Pembersihan karang gigi, pemutihan gigi (bleaching), pembersihan dan pemolesan dengan aliran udara (airflow polishing), penambalan gigi berlubang, dan pencabutan gigi yang sudah tidak bisa dipertahankan lagi merupakan tindakan yang sering dilakukan oleh tenaga kesehatan atau dokter gigi untuk memberi kepuasan kepada pasien dan meningkatkan derajat kesehatan gigi dan mulut pasien. Kunjungan berkala ke dokter gigi sangat diharapkan setiap enam bulan sekali baik ada keluhan maupun tidak untuk menjaga dan mempertahankan kondisi gigi dan mulut (Kusumawardani, 2011)

Dalam kehidupan sehari-hari banyak ditemukan orang merokok baik dikantor, dipasar, ataupun tempat umum lainnya atau bahkan dikalangan rumah tangga sendiri.Kebiasaan merokok dimulai dengan adanya rokok pertama. Umumnya rokok pertama dimulai saat usia remaja. Smet (1994) mengemukakan bahwa merokok terjadi akibat pengaruh lingkungan sosial.

Tahun 2020 Organisasi Kesehatan Dunia (WHO) memperkirakan penyakit yang berkaitan dengan tembakau atau rokok akan menyebabkan 8,4 juta kematian setiap tahun (World Health Organization, 2010). Pada saat ini prevalensi perokok pada laki-laki 11 kali lebih tinggi dibandingkan perempuan. Hal ini disebabkan kurangnya pengetahuan dampak merokok terhadap kesehatan pada usia muda, mudahnya aksebilitas untuk mendapatkan rokok di Indonesia, kurangnya informasi mengenai bahaya merokok dibandingkan dengan gencarnya iklan rokok pada media cetak dan elektronik (Aditama, 1997).

Menurut riset Atlas Tobacco rakyat Indonesia adalah perokok aktif tertinggi ketiga di dunia.Jumlah perokok di Indonesia tahun 2016 mencapai 90 juta jiwa. Indonesia menempati urutan tertinggi prevalensi merokok 
bagi laki-laki di ASEAN yakni sebesar 67,4\% (Atles Tobacco, 2016).

Pada tahun 2018, proporsi merokok pada penduduk umur > 10 tahun di Indonesia 24,3\% (merokok setiap hari), sedangkan di provinsi Sumatera Utara sebesar 22,4\% (merokok setiap hari). Perokok pada usia 20-24 tahun sebanyak 27,3\% (merokok setiap hari), usia 25-29 sebanyak 30,4\% (merokok setiap hari) , usia 30-34 sebanyak $32,2 \%$, usia $35-39$ sebanyak $32,0 \%$, usia $40-44$ sebanyak $31,2 \%$, usia $45-49$ sebanyak $29,6 \%$, dan usia 50 54 sebanyak 28,7\% (Riskesdas, 2018).

Beberapa perubahan kondisi rongga mulut akibat merokok berupa; (1) endapan kecoklatan tar dan pewarnaan struktur gigi; (2) pewarnaan keabu-abuan yang menyebar (difus) dan leoplak di gingiva, dan (3) smoker's plate yang ditandai dengan penonjolan kelenjar mukosa disertai inflamasi di sekitar muara dan eritema yang difus atau gambaran permukaan palatum seperti kerikil (Setianigtyas dkk, 2018).

Rokok dapat berpengaruh terhadap tingkat kebersihan gigi dan mulut. Dimana rokok menyebabkan kelainan pada lidah, gusi, mukosa mulut, palatum yang berupa stomatitis nikotina, infeksi jamur (Candidiasis)dan menyebabkan perubahan pada warna gigi. Efek berbahaya lain dari merokok adalah timbulnya berbagai macam penyakit seperti: karies, kanker paru-paru, kanker rongga mulut (KRM), penyempitan pembuluh darah dan lain sebagainya (Danususantoso, 1993).

Stain merupakan noda yang menempel pada permukaan gigi dikarenakan kebiasaan merokok. Noda tersebut disebabkan oleh nikotin dan tar yang terkandung dalam rokok. Noda tersebut biasanya susah untuk dibersihkan dengan cara menyikat gigi dan menganggu nilai estetis yang terdapat pada gigi (Martariwansyah, 2008).

Citrus merupakan jenis buah dari kumpulan buah dari keluarga besar Rutaceae, buahnya sederhana, besar, dan bulat bujur berukuran $2,5 \mathrm{~cm}-5 \mathrm{~cm}$ garis pusat. Kulitnya berkilat dan licin dan isinya berwarna hijau keputihan atau kekuningan, berair tetapi masam (Room, 2012).Citrus mengandung senyawa kimia yaitu asam malat, asam sitrat, asam askorbat, mineral, dan flavonoid yang bergina bagi dunia kesehatan (Del Rio et al, 2004)

Asam malat (malic acid) adalah dikarboksilat yang mempunyai kemampuan mengoksidasi email gigi. Salah satu buah yang mengandung asam malat adalah buah lemon.Lemon merupakan bahan alami yang efektif dalam pemutihan gigi (Ariana dkk, 2015).

Baking Soda adalah senyawa kimia dengan rumus $\mathrm{NaHCO}_{3}$, senyawa ini disebut Natrium Bikarbonat. Dimana kandungan Natrium Bikarbonat ini dapat menghilangkan stain pada gigi perokok (Holleman, 2001).

Menurut penelitian Ariana dkk 2015, bahan alami yang efektif digunakan untuk membantu melarutkan noda gigi adalah lemon (Citrus limon L). Waktu perendaman ekstrak buah lemon selama 8 jam, 24 jam, 48 jam, dan 72 jam berpegaruh pada proses pemutihan gigi dan peluturan noda gigi.

Pada penelitian yang dilakukan oleh Paramita 2015, baking soda diketahui dapat mengurangi ketebalan stain dengan cara diolesi pasta yang terbuat dari tiga sendok teh baking soda dan satu sendok teh garam dapur dan ditambahkan air secukunya hingga menyerupai pasta gigi, pengolesan hanya dapat dilakukan sekali selama 3 menit . Hasilnya dari 30 responden, 12 diantaranya mengalami perubahan pengurangan stain pada gigi nya.

Menurut penelitian Asih Rahaju dkk 2018, pada sampel 24 gigi premolar permanen yang direndam dalam kombinasi larutan lemon dan natrium bikarbonat dengan konsentrasi $10 \%$ berpotensi dalam memutihkan gigi selama perendaman 8 jam, 24 jam, 48 jam dan 72 jam, kombinasi antara lemon dan natrium bikarbonat menyebabkan perubahan warna gigi yang bermakna pada waktu 48 jam dan 72 jam.

Berdasarkan survei awal yang telah dilakukan pada 10 orang perokok di Kel. Tanjungbalai Kota II, Lk. III, Kec. Tanjungbalai Selatan diperoleh skor indeks stain pada perokok usia 20-55 tahun dengan nilai yang tinggi. Indeks yang digunakan adalah indeks pewarnaan Lobene.

\section{A. Rumusan Masalah}

Berdasarkan latar belakang yang telah diuraikan diatas, maka rumusan masalah penelitian ini "Apakah pemberian citrus dan baking soda efektif dalam mengilangkan stain pada gigi perokok?".

\section{B. Tujuan Penelitian}

1. Untuk mengetahui stain indeks sebelum diberi citrus dengan baking soda pada pria perokok usia 20-55 tahun di kelurahan Tanjungbalai Kota II, Lk. III, kecamatan Tanjungbalai Selatan

2. Untuk mengetahui stain indeks sesudah diberi citrus dengan baking soda pada pria perokok usia 20-55 tahun di kelurahan Tanjungbalai Kota II, Lk. III, kecamatan Tanjungbalai Selatan.

3. Untuk mengetahui penurunan indeks stain sesudah dan sebelum diberi citrus dengan baking soda pada pria perokok usia 20-55 tahun di kelurahan Tanjungbalai Kota II, Lk. III, kecamatan Tanjungbalai Selatan

\section{Manfaat Penelitian}

1. Untuk memberi informasi kepada masyarakat peggunaan citrus dan baking soda dapat menghilangkan stain pada gigi perokok.

2. Untuk memberi informasi kepada kelurahan Tanjungbalai Kota II, Lk. III, kecamatan Tanjungbalai Selatan bahwa peggunaan citrus dan baking soda dapat menghilangkan stain pada gigi perokok.

3. Bagi penelitian selanjutnya dapat digunakan sebagai bahan masukan bagi peneliti yang ingin melanjutkan penelitian dengan topik yang sama dan variabel yang beda di masa yang akan datang dan hasil penelitian ini diharapkan dapat dikembangkan sebagai alternatif bahan alami penghilangan stain pada gigi.

4. Bagi jurusan keperawatan gigi sebagai bahan baca di perpustakaan Politeknik Kesehatan Kementrian Kesehatan RI Medan. 


\section{METODOLOGI PENELITIAN}

\section{A. Jenis dan Desain Penelitian}

Jenis penelitian ini adalah analitik menggunakan metode penelitian quasi experiment atau percobaan yang bertujuan untuk mengetahui suatu gejala atau pengaruh yang timbul akibat dari adanya perlakuan tertentu (Notoatdmojo, 2010). Desain penelitian analitik yang digunakan adalah one group pre and post test, dimana penelitian ini bertujuan untuk mengetahui stain indeks sebelum diberi perlakuan dan sesudah diberi perlakuan pada perokok usia 20-55 tahun di kelurahan Tanjungbalai Kota II, Lk. III, kecamatan Tanjungbalai Selatan.

\section{B. Lokasi dan Waktu Penelitian}

Penelitian ini dilakukan di kelurahan Tanjungbalai Kota II, Lk. III, kecamatan Tanjungbalai Selatan dimulai dari bulan Februari sampai dengan bulan Juni 2019.

\section{Populasi dan Sampel Penelitian}

Populasi adalah keseluruhan objek penelitian atau objek yang diteliti (Arikunto, 2016). Populasi dalam penelitian ini adalah seluruh pria perokok yang berumur 20-55 tahun di kelurahan Tanjungbalai Kota II, Lk. III, kecamatan Tanjungbalai Selatan yang berjumlah 120 orang.

Sampel adalah objek yang akan diteliti dan dianggap mewakili keseluruhan populasi atau sebagian dari objek yang diteliti (Notoatdmodjo, 2017). Pada penelitian ini yang menjadi sampel adalah perokok usia 2055 tahun di kelurahan Tanjungbalai Kota II, Lk. III, kecamatan Tanjungbalai Selatan. Sampel yang diambil menggunakan teknik purposive sampling yaitu sebanyak 30 perokok tersebut yang telah memenuhi kriteria.Purposive sampling adalah salah satu teknik sampling non random sampling dimana peneliti menentukan pengambilan sampel dengan cara menetapkan ciri-ciri khusus yang sesuai dengan tujuan penelitian sehingga diharapkan dapat menjawab permasalahan penelitian. Menurut Arikunto (2016), purposive sampling adalah teknik mengambil sampel dengan tidak berdasarkan random, daerah atau strata, melainkan berdasarkan atas adanya pertimbangan yang berfokus pada tujuan tertentu (Arikunto, 2016).

Pada teknik purposive sampling terdapat kriteria inklusi dan ekslusi dalam pengambilan sampel untuk penelitian. Kriteria inklusi adalah kriteria atau standar yang ditetapkan sebelum penelitian atau penalaahan dilakukan Kriteria ekslusi adalah kriteria pengecualian standar yang ditetapkan sebelum penelitian atau penelaahan.

Kriteria inklusi:

a. Sampel berjenis kelamin laki-laki

b. Sampel berusia 20-55 tahun

c. Sampel merupakan seorang perokok ringan-berat

d. Sampel memiliki gigi indeks yang akan diperiksa

e. Tidak ada gangguan komunikasi/kejiwaan

f. Bersedia diteliti

Kriteria ekslusi:

a. Sampel berjenis kelamin perempuan

b. Sampel berusia $<20$ tahun dan $>55$ tahun c. Tidak perokok

d. Sampel tidak memiliki gigi indeks yang akan diperiksa

e. Terdapat gangguan komunikasi/kejiwaan

f. Tidak bersedia diteliti

\section{Jenis dan Cara Pengumpulan Data}

Data yang dikumpulkan untuk memperoleh jawaban atas masalah penelitian yang dirumuskan. Sumber data yang digunakan dalam penelitian ini yaitu:

1. Data Primer

Data primer adalah data yang langsung didapat saat pemeriksaan melalui indeks stain pada perokok pria usia 20-55 tahun di kelurahan Tanjungbalai Kota II, Lk. III, kecamatan Tanjungbalai Selatan.

2. Data Sekunder

Data sekunder adalah data yang diperoleh dari data yang sudah ada dari pihak kelurahan Tanjungbalai Kota II, Lk. III, kecamatan Tanjungbalai Selatan.

Alat yang digunakan sebagai berikut:

a. OD set : untuk memeriksa stain

b. Nierbekken : untuk tempat pembuangan limbah medis

c. Sikat gigi : untuk membersihkan gigi sampel

Bahan yang digunakan, sebagai berikut:

a. Perasan air lemon dari $2 \mathrm{~kg}$ lemon

b. Baking soda 4 kotak seberat 454 gr/kotak

c. Perbandingan 2:1

d. Pencampuran dilakukan pada uji lab hingga terbentuk gel.

Cara pembuatannya:

1. Cuci buah lemon dengan air lalu dipotong menjadi bagian yang kecil.

2. Masukkan lemon ke juicer ataupun peras buat tersebut.

3. Tampung air perasan jeruk lemon ke dalam gelas.

4. Timbang $20 \mathrm{gr}$ serbuk baking soda, masukkan ke dalam cawan porselin.

5. Ambil air perasan $10 \mathrm{ml}$, tuangkan sedikit demi sedikit ke serbuk baking soda, sambil diaduk. Biarkan gas keluar sampai terbentuk massa kental (gel).

6. Campuran (gel) siap digunakan.

e. Gel untuk menghilangkan stain dari lemon dengan baking soda

f. Cotton pellet dan cotton roll

g. Pasta gigi

h. Lembar pemeriksaan

Dalam penelitian ini, menggunakan instrument penelitian observasi dan lembar pemeriksaan. Observasi adalah suatu prosedur yang berencana yang antara lain meliputi melihat, mendengar, dan mencatat sejumlah aktivitas tertentu atau situasi tertentu yang ada hubungannya dengan masalah yang diteliti. Sedangkan lembar pemeriksaan berisi mengenai apa yang akan diperiksa oleh peneliti (Notoatmodjo, 2017). 
Cara pemeriksaan klinis pada stain yang ditentukan berdasarkan indeks stain Lobene adalah sebagai berikut:

1. Gunakan kaca mulut dan sonde untuk melihat skor stain yang terbentuk pada permukaan gigi.

2. Pemeriksaan stain dilakukan dimulai pada bagian labial dan lingual/palatal gigi anterior, dan di skor secara terpisah antara bagian gingival region (daerah gingiva) yang dilihat adalah intensitasnya dan body region (permukaan gigi) yang dilihat adalah area perluasan. Gigi indeks dan permukaan gigi yang diukur.

\begin{tabular}{|c|c|c|c|c|c|}
\hline $\begin{array}{c}\text { 13: } \\
\text { Labial } \\
\text { dan } \\
\text { palatal }\end{array}$ & $\begin{array}{c}\text { 12: } \\
\text { Labial } \\
\text { dan } \\
\text { palatal }\end{array}$ & $\begin{array}{c}\text { 11: } \\
\text { Labial } \\
\text { dan } \\
\text { palatal }\end{array}$ & $\begin{array}{c}21: \\
\text { Labial } \\
\text { dan } \\
\text { palatal }\end{array}$ & $\begin{array}{c}22: \\
\text { Labial } \\
\text { dan } \\
\text { palatal }\end{array}$ & $\begin{array}{c}\text { 23: } \\
\text { Labial } \\
\text { dan } \\
\text { palatal }\end{array}$ \\
\hline 43 & 42 & 41 & 31 & 32 & 33 \\
\hline $\begin{array}{c}\text { Labial } \\
\text { dan }\end{array}$ & $\begin{array}{c}\text { Labial } \\
\text { dan }\end{array}$ & $\begin{array}{c}\text { Labial } \\
\text { dan }\end{array}$ & $\begin{array}{c}\text { Labial } \\
\text { dan }\end{array}$ & $\begin{array}{c}\text { Labial } \\
\text { dan }\end{array}$ & $\begin{array}{c}\text { Labial } \\
\text { dan }\end{array}$ \\
\hline lingual & lingual & lingual & lingual & lingual & lingual \\
\hline
\end{tabular}

3. Cara penilaian stain adalah sebagai berikut:

\begin{tabular}{|c|c|c|}
\hline Nilai & Deskripsi intensitas & Deskripsi area \\
\hline 0 & Tidak ada pewarnaan & Tidak ada pewarnaan \\
\hline 1 & $\begin{array}{c}\text { Pewarnaan ringan } \\
\text { (kuning-coklat muda } \\
\text { atau abu-abu) }\end{array}$ & $\begin{array}{c}\text { Pewarnaan menutupi } \\
1 / 3 \text { bagian }\end{array}$ \\
\hline 2 & $\begin{array}{c}\text { Pewarnaan sedang } \\
\text { (coklat sedang) }\end{array}$ & $\begin{array}{l}\text { Pewarnaan menutupi } \\
1 / 3-2 / 3 \text { bagian }\end{array}$ \\
\hline 3 & $\begin{array}{c}\text { Pewarnaan berat } \\
\text { (Coklat tua sampai } \\
\text { hitam) }\end{array}$ & $\begin{array}{l}\text { Pewarnaan menutupi } \\
\text { lebih dari } 2 / 3 \text { bagian }\end{array}$ \\
\hline
\end{tabular}

4. Cara pengukuran untuk menentukan indeks stain Lobene yaitu dengan rumus dibawah ini dan nilai yang dihasilkan adalah berupa angka.

a. Skor Intensitas $=$ jumlah seluruh skor intensitas $\overline{\text { jumlah permukaan gigi yang diperiksa }}$

b. Skor Area Perluasan = jumlah seluruh skor area perluasan jumlah permukaan gigi yang diperiksa

c. Jumlah dari kedua skor $=$ skor intensitas $\mathrm{x}$ skor area perluasan jumlah permukaan gigi yang diperiksa

5. Kriteria penilaian indeks stain (Lobene Stain Indeks), yaitu:

a. Apabila angka skor indeks rata-ratanya tinggi maka semakin buruk kriteria stainnya,

b. Apabila angka skor indeks rata-ratanya rendah maka semakin baik kriteria stainnya.

Data hasil penelitian disajikan secara deskriptif kuantitatif yaitu mendeskripsikan hasil penelitian kedalam tabel. Adapun untuk mengetahui efektivitas citrus dengan baking soda sebagai bahan penghilangan stain rokok menggunakan uji dependent t-test (uji $t$-test berpasangan), program computer yang dipakai SPSS.

Pengumpulan data diperoleh dengan melakukan pemeriksaan indeks stain sebelum dan sesudah perlakuan citrus dengan baking soda pada responden yaitu pada perokok pria usia 20-55 tahun di kelurahan Tanjungbalai
Kota II, Lk. III, kecamatan Tanjungbalai Selatan. Data yang dikumpulkan dilakukan observasi sesudah perlakuan.Dalam penelitian ini sampel sebanyak 30 orang. Langkah-langkah penelitian yang dilakukan dalam pengumpulan data adalah sebagai berikut:

a. Kunjungan Pertama

1. Tahap persiapan tempat dan sampel penelitian

2. Menjelaskan perijinan kepada pihak kelurahan bahwa akan diadakan penelitian

3. Menjelaskan tentang prosedur pelaksanaan penelitian dan tujuan dilaksanakan penelitian

4. Menjelaskan waktu pelaksanaan penelitian

5. Menentukan sampel

b. Kunjungan Kedua

1. Mempersiapkan alat dan bahan untuk penelitian, dengan dibantu 2 orang teman sejawat.

2. Menjelaskan tentang penelitian yang akan dilakukan dan memberikan informed consent.

3. Memberikan instruksi kepada responden untuk menyikat gigi.

4. Mempersiapkan gel citrus dengan baking soda.

5. Memeriksa stain indeks sebelum diberi perlakuan gel citrus dengan baking soda.

6. Memberikan informasi tentang cara penggunaan gel citrus dengan baking soda yang hanya boleh digunakan 3 bulan sekali.

7. Isolasi permukaan gingiva agar gel tidak mengenai permukaan gingiva.

8. Mengoleskan gel citrus dengan baking soda sebanyak 5 gr atau sebesar biji kacang hijau menggunakan cotton pellet pada permukaan labial dan lingual gigi anterior dilakukan sekali pengolesan lalu didiamkan selama 3 menit.

9. Membersihkan permukaan gigi menggunakan cotton pellet yang sudah dibasahi sebanyak 2-3 kali.

10. Instruksikan responden untuk menyikat gigi kembali.

11. Memeriksa indeks stain gigi setelah diberi perlakuan.

12. Mencatat hasil pemeriksaan pada lembar pemeriksaan.

Catatan : Pemeriksaan pada 30 sampel dilakukan oleh 1 orang peneliti dan 2 orang yang membantu penelitian, dimana tugasnya:

1) Satu orang membantu menyiapkan alat dan bahan serta membantu mengarahkan responden untuk menyikat gigi setelah selesai perlakuan.

2) Satu orang membantu menulis hasil pemeriksaan.

\section{E. Pengolahan Data dan Analisa Data}

Data yang telah dikumpulkan diolah dengan manual dengan langkah-langkah segai berikut:

\section{Editing}

Memeriksa kelengkapan formulir pemeriksaan dengan tujuan agar data yang dimaksud dapat diolah secara benar.

2. Coding

Dalam langkah ini peneliti mengubah formulir pemeriksaan menjadi bentuk angka-angka yang 
berhubungan dengan variabel peneliti untuk memudahkan dalam pengolahan data.

3. Scoring

Dalam langkah ini peneliti menghitung skor yang diperoleh berdasarkan hasil pemeriksaan yang dilakukan pada perokok.

4. Tabulating

Memasukkan hasil perhitungan dalam bentuk tabel, untuk melihat rata-rata dan persentase dari pemeriksaan yang diperoleh.

\section{Analisa Bivariat}

Untuk memperoleh gambaran keadaan stain sebelum dan sesudah pemberian citrus dengan baking soda terhadap penghilangan stain pada pria perokok usia 20-55 tahun di Kelurahan Tanjungbalai Kota II, Lk. III, Kecamatan Tanjungbalai Selatan.

\section{Analisa Bivariat}

Untuk mengetahui efektivitas pemberian gel citrusdengan baking soda terhadap penghilangan stain pada pria perokok usia 20-55 tahun di Kelurahan Tanjungbalai Kota II, Lk. III, Kecamatan Tanjungbalai Selatan yang dilakukan dengan uji statistik t-test berpasangan.

\section{HASIL DAN PEMBAHASAN}

\section{A. Hasil Penelitian}

Data yang dikumpulkan adalah hasil penelitian yang dilakukan terhadap pria perokok usia 20-55 tahun di Lk. III Kelurahan Tanjungbalai Kota II, Kecamatan Tanjungbalai Selatan. Setelah data terkumpulkan dibuatlah analisa data dengan cara membuat tabel distribusi frekuensi untuk masing-masing responden, kemudian dilakukan pengolahan data statistik dengan uji t-Test.

\section{Analisa Univariat}

a. Analisa univariat dalam penelitian ini bertujuan untuk melihat gambaran keadaan stain sebelum dan sesudah dan penurunan stain indeks sebelum dan sesudah diberikan gel citrus dengan baking soda pada pria perokok usia 2055 tahun di Lk. III Kelurahan Tanjungbalai Kota II, Kecamatan Tanjungbalai Selatan.

$$
\text { Tabel } 4.1
$$

Distribusi Frekuensi Keadaan Stain Sebelum dan Sesudah dan Penurunan Stain Indeks Sebelum dan Sesudah Diberikan

Gel Citrus dengan Baking Soda Pada Perokok Usia 20-55

Tahun di Lk. III Kelurahan Tanjungbalai Kota II, Kecamatan

\begin{tabular}{|c|c|c|c|}
\hline \multirow{2}{*}{ Pengukuran } & \multicolumn{2}{|c|}{$\begin{array}{c}\text { Rata-rata Pewarnaan } \\
\text { Gigi } \\
\end{array}$} & \multirow{2}{*}{$\begin{array}{c}\text { Penurunan } \\
\text { Stain Indeks } \\
\text { Sebelum Dan } \\
\text { Sesudah Diber } \\
\text { Perlakuan } \\
\end{array}$} \\
\hline & Sebelum & Sesudah & \\
\hline $\begin{array}{l}\text { Intensitas } \\
\text { Lobene }\end{array}$ & 0,879 & 0,408 & 0,471 \\
\hline Area Lobene & 1,084 & 0,493 & 0,591 \\
\hline $\begin{array}{l}\text { Gabungan } \\
\text { Lobene }\end{array}$ & 0,081 & 0,037 & 0,044 \\
\hline
\end{tabular}

Berdasarkan tabel di atas menunjukkan bahwa keadaan stain rata-rata sebelum diberikan diberikan gel citrus dengan baking soda pada perokok usia 20-55 tahun di Lk. III Kelurahan Tanjungbalai Kota II, Kecamatan Tanjungbalai Selatan, intesitas lobene sebesar 0,879, dengan area lobene sebesar 1,084, dan gabungan lobene 0,081 . Sementara untuk keadaan stain setelah diberikan gel citrus dengan baking soda pada perokok usia 20-55 tahun di Lk. III Kelurahan Tanjungbalai, Kecamatan Tanjungbalai Selatan, intensitas lobene sebesar 0,408, area lobene sebesar 0,493, gabungan lobene 0,037. Jadi penurunan stain indeks untuk intensitas lobenenya sebesar 0,471, area lobenenya sebesar 0,591, dan gabungan lobenenya sebesar 0,044 .

b. Analisa univariat dalam penelitian ini bertujuan untuk melihat gambaran kelompok umur pada pria perokok usia 20-55 tahun di Lk. III, Kelurahan Tanjungbalai Kota II, Kecamatan Tanjungbalai Selatan.

Tabel 4.2

Distribusi Frekuensi Pengelompokkan Umur Menurut Depkes RI Pada Pria Perokok Usia 20-55 Tahun di Lk. III Kelurahan Tanjungbalai Kota II, Kecamatan Tanjungbalai Selatan

\begin{tabular}{cccc}
\hline \multicolumn{2}{c}{ Kategori Umur } & $\mathrm{n}$ & $\%$ \\
\hline Masa Remaja Akhir & 17-25 Tahun & 17 & 56,67 \\
Masa Dewasa Awal & 26-35 Tahun & 10 & 33,33 \\
Masa Dewasa Akhir & 36-45 Tahun & 2 & 6,67 \\
Masa Lansia Awal & 46-55 Tahun & 1 & 3,33 \\
\hline Jumlah & & $\mathbf{3 0}$ & $\mathbf{1 0 0}$ \\
\hline
\end{tabular}

Berdasarkan tabel diatas menunjukkan bahwa pengelompokkan umur pada pria perokok usia 20-55 tahun di Lk. III Kelurahan Tanjungbalai Kota II, Kecamatan Tanjungbalai Selatan, yang berada dalam kategori masa akhir remaja (17-25 tahun) sebanyak 17 orang $(56,67 \%)$, masa dewasa awal (26-35 tahun) sebanyak 10 orang $(33,33 \%)$, masa dewasa akhir (3645 tahun) sebanyak 2 orang $(6,67 \%)$, dan masa lansia awal (46-50 tahun) sebanyak 1 orang $(3,33 \%)$.

c. Analisa univariat dalam penelitian ini bertujuan untuk melihat gambaran banyak merokok dalam sehari pada pria perokok usia 20-55 tahun di Lk. III Kelurahan Tanjungbalai Kota II, Kecamatan Tanjungbalai Selatan Tabel 4.3

Distribusi Frekuensi Banyaknya Merokok dalam Sehari Pada Pria Perokok Usia 20-55 Tahun di Lk. III Kelurahan Tanjungbalai Kota II, Kecamatan Tanjungbalai Selatan

\begin{tabular}{ccc}
\hline $\begin{array}{c}\text { Banyak merokok } \\
\text { dalam sehari }\end{array}$ & $\mathrm{n}$ & $(\%)$ \\
\hline 1-10 Batang & 18 & 60 \\
11-20 Batang & 4 & 13,33 \\
>20 Batang & 8 & 26,67 \\
\hline Jumlah & $\mathbf{3 0}$ & $\mathbf{1 0 0}$ \\
\hline
\end{tabular}

Berdasarkan tabel diatas menunjukkan bahwa persentase dari 30 orang perokok usia 20-55 tahun di Lk. III Kelurahan Tanjungbalai Kota II, Kecamatan Tanjungbalai Selatan banyak merokok dalam sehari sebanyak 1-10 batang sebanyak 18 orang (60\%), 11-20 
batang sebanyak 4 orang $(13,33 \%), \quad>20$ batang sebanyak 8 orang $(26,27 \%)$.

\section{Analisa Bivariat}

Analisa bivariat dalam penelitian ini bertujuan untuk melihat efektivitas pemberian citrus dengan baking soda terhadap penghilangan stain pada pria perokok usia 20-55 tahun di Lk.III kelurahan Tanjungbalai Kota II, Kecamatan Tanjungbalai Selatan.

Tabel 4.4

Statistik Deskriptif Skor Intensitas Sebelum dan Sesudah Pemberian Citrus dengan Baking Soda Terhadap

Penghilangan Stain Pada Pria Perokok Usia 20-55 Tahun di Lk.III Kelurahan Tanjungbalai Kota II, Kecamatan Tanjungbalai Selatan $(\mathrm{n}=30)$

\begin{tabular}{cccccc}
\hline $\begin{array}{c}\text { Variabel } \\
\text { Skor } \\
\text { Intensitas }\end{array}$ & $\begin{array}{c}\text { Rata- } \\
\text { Rata }\end{array}$ & $\begin{array}{c}\text { Standar } \\
\text { Deviasi }\end{array}$ & $\begin{array}{c}\text { Standar } \\
\text { Eror }\end{array}$ & $\begin{array}{c}\mathrm{P} \\
\text { Value }\end{array}$ & Jumlah \\
\hline $\begin{array}{c}\text { Sebelum } \\
\text { Pemberian }\end{array}$ & & & & & \\
$\begin{array}{c}\text { Gel Citrus } \\
\text { Baking } \\
\text { Soda }\end{array}$ & 0,8790 & 0,60541 & 0,11053 & & \\
Sesudah & & & & & \\
Pemberian & & & & 0,000 & 30 \\
Gel Citrus & 0,4083 & 0,64713 & 0,11815 & & \\
Baking & & & & & \\
Soda & & & & & \\
\hline
\end{tabular}

Tabel 4.4 dapat dilihat bahwa rata-rata skor intensitas sebelum diberikan perlakuan adalah 0,8790 dengan standard deviasi 0,60541, dan dapat diketahui rata-rata skor intensitas sesudah perlakuan adalah 0,4083 dengan standard deviasi 0,64713. Terlihat perbedaan mean antara sebelum dan sesudah diberikan perlakuan gel citrus dengan baking soda adalah 0,4707 dengan standard deviasi 0,04172. Berdasarkan uji statistikpaired sample t-test didapatkan pValue $=0,000$ lebih kecil dari nilai alpha $5 \%(0,05)$. Berdasarkan syarat $\mathrm{p}<0,05$, maka disimpulkan bahwa pemberian citrus dengan baking soda terhadap perokok ternyata cukup efektif untuk menghilangka stain pada pria perokok.

Tabel 4.5

Statistik Deskriptif Skor Area Sebelum dan Sesudah Pemberian Citrus dengan Baking Soda Terhadap Penghilangan Stain Pada Pria Perokok Usia 20-55 Tahun di Lk.III Kelurahan Tanjungbalai Kota II, Kecamatan Tanjungbalai Selatan $(\mathrm{n}=30)$

\begin{tabular}{cccccc}
\hline Variabel & Rata- & $\begin{array}{c}\text { Standar } \\
\text { Skor Area }\end{array}$ & $\begin{array}{c}\text { Standar } \\
\text { Reviasi }\end{array}$ & $\begin{array}{c}\text { P } \\
\text { Ealue }\end{array}$ & \multirow{2}{*}{ Jumlah } \\
\hline $\begin{array}{c}\text { Sebelum } \\
\text { Pemberian }\end{array}$ & & & & & \\
$\begin{array}{c}\text { Gel Citrus } \\
\text { Baking }\end{array}$ & 1,0840 & 0,59890 & 0,10934 & & \\
$\quad$ Soda & & & & & \\
$\begin{array}{c}\text { Sesudah } \\
\text { Pemberian }\end{array}$ & & & & 0,000 & 30 \\
$\begin{array}{c}\text { Gel Citrus } \\
\text { Baking }\end{array}$ & 0,4931 & 0,70846 & 0,12935 & & \\
Soda & & & & & \\
& 0,5909 & 0,10956 & 0,02001 & & \\
\hline
\end{tabular}

Tabel 4.5 dapat dilihat bahwa rata-rata skor area sebelum diberikan perlakuan adalah 1,0840 dengan standard deviasi 0,59890, dan dapat diketahui rata-rata skor area sesudah perlakuan adalah 0,4931 dengan standard deviasi 0,70846. Terlihat perbedaan mean antara sebelum dan sesudah diberikan perlakuan gel citrus dengan baking soda adalah 0,5909 dengan standard deviasi 0,10956. Berdasarkan uji statistikpaired sample t-test didapatkan pValue 0,000 lebih kecil dari nilai alpha 5\% $(0,05)$. Berdasarkan syarat $\mathrm{p}<0,05$, maka disimpulkan bahwa pemberian citrus dengan baking soda terhadap perokok ternyata cukup efektif untuk menghilangkan stain pada pria perokok.

Tabel 4.6

Statistik Deskriptif Gabungan Skor Sebelum dan Sesudah Pemberian Citrus dengan Baking Soda Terhadap

Penghilangan Stain Pada Pria Perokok Usia 20-55 Tahun di Lk.III Kelurahan Tanjungbalai Kota II, Kecamatan Tanjungbalai Selatan $(\mathrm{n}=30)$

\begin{tabular}{cccccc}
\hline $\begin{array}{c}\text { Variabel } \\
\text { Gabungan } \\
\text { Skor }\end{array}$ & $\begin{array}{c}\text { Rata- } \\
\text { Rata }\end{array}$ & $\begin{array}{c}\text { Standar } \\
\text { Deviasi }\end{array}$ & $\begin{array}{c}\text { Standar } \\
\text { Eror }\end{array}$ & $\begin{array}{c}P \\
\text { Value }\end{array}$ & Jumlah \\
\hline $\begin{array}{c}\text { Sebelum } \\
\text { Pemberian }\end{array}$ & & & & & \\
$\begin{array}{c}\text { Gel Citrus } \\
\text { Baking }\end{array}$ & 0,0818 & 0,06618 & 0,01208 & & \\
$\quad \begin{array}{l}\text { Soda } \\
\text { Sesudah }\end{array}$ & & & & & \\
$\begin{array}{c}\text { Pemberian } \\
\text { Gel Citrus }\end{array}$ & 0,0377 & 0,07265 & 0,01326 & & \\
Baking & & & & & \\
Soda & & & & & \\
& 0,0441 & 0,00647 & 0,00118 & \\
\hline
\end{tabular}

Tabel 4.6 dapat dilihat bahwa rata-rata gabungan skor sebelum diberikan perlakuan adalah 0,0818 dengan standard deviasi 0,06618, dan dapat diketahui rata-rata gabungan skor sesudah perlakuan adalah 0,0377 dengan standard deviasi 0,07265. Terlihat perbedaan mean antara sebelum dan sesudah diberikan perlakuan gel citrus dengan baking soda adalah 0,0441 dengan standard deviasi 0,00647. Berdasarkan uji statistikpaired sample t-test didapatkan pValue 0,000 lebih kecil dari nilai alpha 5\% (0,05). Berdasarkan syarat $\mathrm{p}<0,05$, maka disimpulkan bahwa pemberian citrus dengan baking soda terhadap perokok ternyata cukup efektif untuk menghilangkan stain pada pria perokok.

\section{B. Pembahasan}

Banyaknya sampel yang berusia berumur 1725 tahun atau dalam kategori masa akhir remaja adalah salah satu faktor bahwa yang pertama kali memperkenalkan remaja terhadap perilaku merokok adalah lingkungan.Rasa agar dapat diterima sebagai anggota dari lingkungan perokok menstimulasi remaja untuk mencoba hal tersebut (Susanto dkk, 2018) dalam Geiss dkk (2007).Sikap sebagian remaja Indonesia juga telah menganggap bahwa merokok adalah suatu kebutuhan yang tidak bisa dielakkan karena rokok dianggap dapat menghilangkan kekecewaan dan stres. 
Perilaku kesehatan seseorang atau masyarakat dipengaruhi oleh tiga faktor yaitu predisposing factors (pengetahuan, sikap, kepercayaan, tingkat sosioekonomi, keyakinan, nilai-nilai, dan sebagainya), enabling factors (lingkungan fisiktersedia atau tidaknya fasilitas sarana kesehatan) dan reinforcing factors (sikap dan perilaku petugas kesehatan yang merupakan kelompok referensi dari perilaku masyarakat) (Susanto dkk, 2018) dalam Aditama, (1997). Menurut Green, predisposing factors merupakan faktor yang paling mempengaruhi seseorang. Kurangnya pengetahuan masyarakat tentang kesehatan gigi dan mulut menyebabkan tingkat kesehatan gigi dan mulut yang buruk, sehingga masyarakat merasa tidak puas dengan penampilan giginya.Terjadinya perubahan warna pada gigi, pewarnaan gigi, halitosis, kalkulus dan plak merupakan contoh ketidakpuasan masyarakat tersebut sehingga perusahaan dari produk-produk berusaha mengembangkan pasta gigi yang diduga dapat mengurangi pewarnaan gigi dan penghilangan stain pada gigi (Susanto dkk, 2018) dalam Diana, (2000).

Pada penelitian ini, peneliti ingin mengetahui efektivitas pemberian citrus dengan baking soda terhadap penghilangan stain pada pria perokok usia 2055 tahun di Lk.III Kelurahan Tanjungbalai Kota II, Kecamatan Tanjungbalai Selatan dengan jumlah sampel 30 orang. Penulis menggunakan desain penelitian analitik dengan menggunakan uji Dependent t-Test. Penelitian ini dilakukan dengan menggunakan data primer yaitu data yang langsung diambil dari objek peneliti berupa pemberian gel citrus dengan baking soda dan keadaan stain sebelum dan sesudah diberi perlakuan.

Dari tabel 4.1 memperlihatkan rata-rata pewarnaan gigi sebelum dan sesudah menggunakan gel citrus dengan baking soda terdapat penurunan stain indeks pada pengukuran intensitas Lobene sebanyak 0,471, area Lobene sebanyak 0,591, maupun gabungan Lobene sebanyak 0,044.

Dari tabel 4.2 memperlihatkan bahwa sebagian besar sampel atau perokok berusia 17-25 tahun atau sebanyak 56,67\% di Lk. III Kelurahan Tanjungbalai Kota II, Kecamatan Tanjungbalai Selatan.

Dari tabel 4.3 memperlihatkan bahwa sebagian besar sampel mengonsumsi rokok dalam sehari antara 1-10 batang atau sebanyak $60 \%$ di Lk. III, Kelurahan Tanjungbalai Kota II, Kecamatan Tanjungbalai Selatan.

Dari hasil uji statistika dengan uji Dependent t-Test dengan nilai p $(0,000)<\alpha(0,05)$, bahwa penggunaan gel citrus dengan baking soda efektif dalam penghilangan stain pada gigi perokok.

Menurut Asih Rahaju dkk (2018), asam sitrat pada lemon diketahui memilliki kemampuan dalam memutihkan gigi yang berubah warna karena memiliki gugus $\mathrm{OH}$ yang berpotensi menjadi oksidator sama seperti kandungan pada hydrogen peroksida. Natrium bikarbonat diketahui efektif sebagai bahan pemutih gigi karena adanya reaksi oksidasi antara natrium bikarbonat dan oksigen. Struktur kristal natrium bikarbonat yang bersifat besar dan lembut dapat melepaskan noda pada gigi.
Kombinasi ektrak air lemon dan natrium bikarbonat (baking soda) dengan konsentrasi $10 \%$ memiliki potensi memutihkan gigi selama perendaman 8 jam, 24 jam, 48 jam, dan 72 jam tetapi yang menyebabkan perubahan warna yang bermakna pada waktu 48 jam sampai 72 jam. (Asih Rahaju, 2018).

Jadi terdapat hubungan antara penggunaan citrus dengan baking soda terhadap pengurangan stain.

Menurut Ariana dkk (2015), asam malat (malicacid) adalah dikarboksilat yang mempunyai kemampuan memutihkan gigi dengan cara mengoksidasi permukaan email gigi. Salah satu buah yang mengandung asam malat adalah buah lemon.Buah lemon merupakan salah satu buah tropis yang mudah ditemukan di Indonesia dan dapat dimanfaatkan sebagai bahan alternatif peningkatan warna gigi atau bahan alami dalam memutihkan gigi secara aman dan lebih murah.

Perendaman gigi dalam perasan buah lemon dengan waktu 8 jam, 24 jam, 48 jam, dan 72 jam menunjukkan perbedaan nilai warna gigi pada perendaman 24 jam, 48 jam, dan 72 jam dan tidak ada perbedaan pada perendaman 8 jam. Dari hasil tersebut dapat disimpulkan bahwa perasan buah lemon dapat berpengaruh terhadap peningkatan warna gigi, tetapi semakin lama waktu perendaman diduga akan menyebabkan porusitas pada gigi.

Menurut Dian Paramitha (2015), Baking soda adalah senyawa kimia dengan rumus $\mathrm{NaHCO}_{3}$, senyawa ini disebut natrium bikarbonat. Dimana kandungan natrium bikarbonat ini dapat menghilangkan stain pada gigi perokok. Baking soda salah satu pembersih yang efektif, dapat digunakan menghilangkan perubahan noda pada gigi. Keuntungan lain dari baking soda adalah dapat menghilangkan bau mulut dan dapat memutihkan gigi karena baking soda dapat mengurangi pertumbuhan bakteri dan membuang penumpukan plak.

Pengolesan gigi dengan pasta yang terbuat dari baking soda dengan campuran garam dan air dioleskan pada permukaan gigi selama 3 menit dengan dilakukan sekali pengolesan dan dilihatlah perubahan stain pada gigi responden. Dari 30 responden 12 diantaranya mengalami pengurangan stain pada gigi. Hal tersebut terbukti bahwa baking soda adalah salah satu alternatif yang bisa digunakan untuk mengurangi stain pada gigi.

Pengolesan gel citrus dengan baking soda hanya dilakukan selama 3 menit dengan sekali pengolesan tanpa mengenai jaringan sekitar mulut yang tidak ingin dikenai gel tersebut. Penggunaannya 3 bulan sekali untuk menghindari efek abrasi atau pengikisan pada enamel gigi.

\section{Simpulan}

Dari hasil penelitian yang telah dilakukan oleh peneliti maka dapat disimpulkan bahwa:

1. Rata-rata pewarnaan gigi sebelum dan sesudah menggunakan gel citrus dengan baking soda terdapat penurunan stain indeks pada pengukuran intensitas Lobene sebanyak 0,471, area Lobene 
sebanyak 0,591, maupun gabungan Lobene sebanyak 0,044.

2. Pengelompokkan umur pada pria perokok di Lk. III Kelurahan Tanjungbalai Kota II, Kecamatan Tanjungbalai Selatan menunjukkan bahwa sebagian besar subjek berusia 17-25 tahun atau sebanyak $56,67 \%$.

3. Banyaknya merokok dalam sehari pada pria perokok di Lk. III Kelurahan Tanjungbalai Kota II, Kecamatan Tanjungbalai Selatan diketahui bahwa sebagian besar sampel mengonsumsi rokok dalam sehari antara 1-10 batang atau sebanyak $60 \%$.

4. Efektifnya pemberian gel citrus dengan baking soda terhadap penghilangan stain pada pria perokok usia 20-55 tahun di Lk. III Kelurahan Tanjungbalai Kota II, Kecamatan Tanjungbalai Selatan dengan nilai $\mathrm{p}$ 0,000 untuk $\alpha 0,05$.

\section{Saran}

Sesuai dengan hasil penelitian yang telah dilakukan maka peneliti memberikan saran sebagai berikut:

1. Memberikan informasi kepada masyarakat Lk. III Kelurahan Tanjungbalai Kota II Kecamatan Tanjungbalai Selatan bahwa citrus dengan baking soda dapat menghilangkan stain pada perokok, boleh menggunakan gel tersebut untuk penghilangan stain dengan waktu dan cara yang dianjurkan dan agar mengurangi konsumsi rokok supaya terhindar dari masalah kesehatan yang sangat mematikan dan agar gigi terlihat putih bersih.

2. Memberikan informasi kepada kelurahan Tanjungbalai Kota II, Lk. III, kecamatan Tanjungbalai Selatan bahwa peggunaan citrus dan baking soda dapat menghilangkan stain pada gigi perokok

3. Kepada peneliti selanjutnya diharapkan untuk mengkaji lebih banyak sumber maupun referensi yang terkait dengan sarana prasarana pendidikan maupun efektivitas proses pembelajaran agar hasil penelitiannya dapat lebih banyak dan lebih lengkap lagi.

\section{Daftar Pustaka}

Arikunto, S., 2016, Prosedur Penelitian Suatu Pendekatan Praktik, Jakarta: Rineka Cipta.

Ariana, T.R, dkk., 2015, Pengaruh Perasan Buah Lemon Terhadap Peningkatan Warna Gigi, Medali Jurnal, Vol. 2(1), 74-78.

Astawan, M, 2008, Seri Kesehatan Keluarga: Sehat dengan Buah, Jakarta: DIAN RAKYAT.

Boedihardjo, 1985, Pemeliharaan Kesehatan Gigi Keluarga, Surabaya: Universitas Airlangga Press.

Chyntia, K, dkk, 2015, Extrinsic Tooth Discolouration, An Update Review, Dent Tribune Middle East and Africa, 6-10.

Hidayat, R dan A Tandiari, 2016, Kesehatan Gigi dan Mulut, Yogyakarta: CV ANDI OFFSET.
Holleman, A.F dan E Wilberg, 2001, Inorganic Chemistry, Sandiego: Academic Press.

Ireland, R., 2015, Kamus Kedokteran Gigi, Jakarta: EGC.

Kusumawardani, E., 2011, Buruknya Kesehatan Gigi dan Mulut, Yogyakarta: SIKLUS.

Lalage, Z., 2013, 101 Khasiat Selangit Buah \& Sayur, Klaten: Galmas Publisher.

Langlais, R.P., 2013, Atlas BerwarnaLesi Mulut yang Sering Ditemukan, Jakarta: EGC.

Malholtra, R, dkk, 2010, Nicotine and Periodontal Tisues, J Indian Soc Periodontal, Vol. 14(1), 72-9.

Martariwansyah, 2008, Gigiku Kuat Mulutku Sehat, Bandung: Karya Kita.

Mehrotra, V, dkk, 2014, Tell Tale Shades of Disclored Teeth: A Review, Indian Journal of Dental Science, Vol. 6(2), 95-9.

Mercola, J., 2012, Baking Soda Use This to Remove Splinters and Many Other Health Needs.

Paramita, D., 2015, Pemanfaatan Baking Soda untuk Membersihkan Stain Pada Gigi Perokok di Puskesmas Karang Pule, GaneÇ Swara, Vol. 9, 108-111.

Puspaningtyas, D.E, Y.I Prasetyaningrum, 2014, Variasi Favorit Infused Water Berkhasiat, Jakarta: FMedia.

Rahaju, A, dkk., 2018, Potensi Kombinasi Ekstrak Air Lemon (Citrus limon L) dan Natrium Bikarbonat Sebagai Larutan Pemutih Gigi (in vitro), Media Kartika, Vol.2 (1): 64-75.

Riset Kesehatan Dasar (RISKESDAS), 2018, Badan Penelitian dan Pengembangan Kesehatan Kementrian RI Tahun 2018. Jakarta: Balitbangkes.

Sastrawan, 2015, Meninjau Kriteria Inklusi dan Ekslusi dalam Pengambilan Sampel Penelitian di http://kamuskesehatan.com/arti/kriteria-inklusiekslusi/, (diakses 24 Maret 2019).

Setyaningsih, K.D dan Irmawati, 2015, Hidup Sehat untuk Golongan Darah A, Jakarta: CV Penerbit Euthenia Prima.

Setyaningsih, D dan A.F Erwana, 2018, GIGI - Merawat dan Menjaga Kesehatan Gigi \& Mulut, Yogyakarta: Rapha Publishing

Smet, B., 1994, Psikologi Kesehatan, Semarang: PT Gramedia

Srigupta, A., 2004, Panduan Singkat Kesehatan Gigi dan Mulut, Jakarta: Prestasi Pustaka.

Susanto, A dkk., 2018, Efek Pasta Gigi Kalsium Karbonat dan Hydrated Silica Terhadap Pewarnaan Gigi Perokok, Laporan Penelitian, 33-35.

Sutomo, B dan D Kurnia., 2016, 378 Resep Jus \& Ramuan Herbal, Jakarta: Kawan Pustaka.

Terezhalmy, G.T dkk., 2004, Tooth Whitening Through The Removal Of Extrinsic Stain With A Power Toothbrush: Result Of Four Randomized, Examiner Blind, Positive Controlled Clinical Studies, American Journal Dentistry, Vol.17, 18A24A.

World Health Organization, Indonesia National Health System Profile,Indonesia: WHO, 2010, [disitasi Oktober 2013] diakses dari: http://www/search.who.int/LinkFiles/Indonesia_C HP-Indonesia.pdf.,(diakses 24 Februari 2019). 